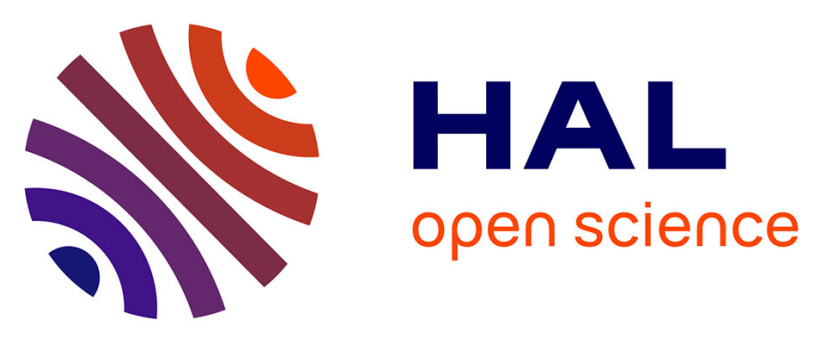

\title{
Image analysis of immune cell patterns in the human mammary gland during the menstrual cycle refines lymphocytic lobulitis
}

Nadine S. Schaadt, Juan Carlos López Alfonso, Ralf Schönmeyer, Anne Grote, Germain Forestier, Cédric Wemmert, Nicole Krönke, Mechthild Stoeckelhuber, Hans Kreipe, Haralampos Hatzikirou, et al.

\section{To cite this version:}

Nadine S. Schaadt, Juan Carlos López Alfonso, Ralf Schönmeyer, Anne Grote, Germain Forestier, et al.. Image analysis of immune cell patterns in the human mammary gland during the menstrual cycle refines lymphocytic lobulitis. Breast Cancer Research and Treatment, 2017, 164 (2), pp.305 - 315. $10.1007 / \mathrm{s} 10549-017-4239-\mathrm{z}$. hal-01875860

\section{HAL Id: hal-01875860 https://hal.science/hal-01875860}

Submitted on 17 Sep 2018

HAL is a multi-disciplinary open access archive for the deposit and dissemination of scientific research documents, whether they are published or not. The documents may come from teaching and research institutions in France or abroad, or from public or private research centers.
L'archive ouverte pluridisciplinaire HAL, est destinée au dépôt et à la diffusion de documents scientifiques de niveau recherche, publiés ou non, émanant des établissements d'enseignement et de recherche français ou étrangers, des laboratoires publics ou privés. 


\title{
Image analysis of immune cell patterns in the human mammary gland during the menstrual cycle refines lymphocytic lobulitis
}

\author{
Nadine S Schaadt • Juan Carlos López Alfonso • Ralf Schönmeyer • \\ Anne Grote · Germain Forestier • Cédric Wemmert • Nicole Krönke • \\ Mechthild Stoeckelhuber • Hans H Kreipe - Haralambos Hatzikirou • \\ Friedrich Feuerhake
}

Received: date / Accepted: date

\begin{abstract}
Purpose: To improve microscopic evaluation of immune cells relevant in breast cancer oncoimmunology, we aim at distinguishing normal infiltration patterns from lymphocytic lobulitis by advanced image analysis. We consider potential immune cell variations due to the menstrual cycle and oral contraceptives in nonneoplastic mammary gland tissue.
\end{abstract}

Methods: Lymphocyte and macrophage distributions were analyzed in the anatomical context of the resting mammary gland in immunohistochemically stained digital whole slide images obtained from 53 reduction mammoplasty specimens. Our image analysis workflow

NS Schaadt · A Grote $\cdot$ N Krönke $\cdot$ HH Kreipe $\cdot$ F Feuerhake Institute of Pathology, Hannover Medical School, CarlNeuberg-Straße 1, 30625 Hannover, Germany

Tel.: +49-511-5325238

Fax: +49-511-53218512

E-mail: Feuerhake.Friedrich@mh-hannover.de

C Wemmert

ICube, University of Strasbourg, 300 bvd Sebastien Brant, 67412 Illkirch, France

JCL Alfonso · H Hatzikirou

Department of Systems Immunology and Braunschweig Integrated Centre of Systems Biology, Helmholtz Centre for Infection Research, Braunschweig, Germany

R Schönmeyer

Definiens AG, Bernhard-Wicki-Straße 5, 80636 Munich, Germany

G Forestier

MIPS, University of Haute Alsace, 12 rue des Freres Lumiere, 68093 Mulhouse, France

M Stoeckelhuber

Department of Oral and Maxillofacial surgery, Technische Universität München, Ismaningerstraße 22, 81675 Munich, Germany included automated regions of interest detection, immune cell recognition, and co-registration of regions of interest.

Results: In normal lobular epithelium, seven $\mathrm{CD} 8^{+}$ lymphocytes per 100 epithelial cells were present on average and about $70 \%$ of this T-lymphocyte population was lined up along the basal cell layer in close proximity to the epithelium. The density of $\mathrm{CD} 8^{+} \mathrm{T}$-cell was 1.6 fold higher in the luteal than in the follicular phase in spontaneous menstrual cycles and 1.4 fold increased under influence of oral contraceptives, and not co-localized with epithelial proliferation. $\mathrm{CD} 4^{+} \mathrm{T}$-cells were infrequent. Abundant $\mathrm{CD}_{163^{+}}$macrophages were widely spread, including the interstitial compartment, with minor variation during the menstrual cycle.

Conclusions: Spatial patterns of different immune cell subtypes determine the range of normal, as opposed to inflammatory conditions of the breast tissue microenvironment. Advanced image analysis enables quantification of hormonal effects, refines lymphocytic lobulitis, and shows potential for comprehensive biopsy evaluation in oncoimmunology.

Keywords lymphocytic lobulitis · digital pathology · oncoimmunology · object-based image analysis . menstrual cycle $\cdot$ hormonal fluctuations

\section{Introduction}

Lymphocytic lobulitis (LLO) is an inflammatory condition previously observed in normal breast tissue [8], autoimmune disease [24,38], nonmalignant mammary glands from patients with germline BRCA1/2 mutations [19], and as peritumoral phenomenon in breast 
cancer $[7,25,11]$. So far, LLO has mainly been described by absolute immune cell numbers per lobule of the mammary gland $[7,25,19,16,8]$. While the reported descriptions that rely solely on estimated cell counts have captured important features of LLO, there remains some degree of uncertainty. The anatomical term "lobule" as a reference area can be readily identified, but size, shape, and cellular content of cross sections at different levels can be highly variable. Further, individual observers may consider different structures as "representative lobules". Moreover, the potential influence of hormonal fluctuations on immune cell infiltrates has not yet been considered. Therefore, it cannot be excluded that current definitions of LLO may miss important aspects of the dynamic temporal or spatial inflammatory tissue microenvironment (iTME) variability.

Previously, we developed context-related immune cell evaluation in single microscopic images [22], improved color deconvolution in digital whole slide images (WSIs) [42], and automated detection of lobular structures adjacent to tumors [15].

In this study, we implemented an advanced digital image analysis workflow specifically adjusted to iTME in breast tissue to characterize the range of normal immune presence in the healthy breast tissue and distinguish normal, potentially fluctuating immune surveillance from pathological conditions. We consider LLO as a use case for comprehensive evaluation of iTME in an anatomically well-defined context with clinical relevance. This addresses the emerging challenge of comprehensive immune cell evaluation in the era of oncoimmunology and paves the way for computer-aided breast cancer biopsy analysis. Therefore, we acquired largescale spatial data on immune cells in WSIs by combining novel technologies $[3,36]$ in a modular approach in breast tissue of healthy women who underwent reduction mammoplasty and relate the image-based data with the hormonal status of the patients at time of surgery.

\section{Materials and Methods}

\subsection{Tissue samples}

Breast tissue was obtained from 53 premenopausal healthy women who underwent reduction mammoplasty and provided a detailed reproductive clinical history $[12,13$, 1]. 20 women were taking oral contraceptives at time of surgery (Table 1). The phase of the menstrual cycle at the day of the surgical procedure was determined by documentation of the periods prior and after operation (details in Section 1.1.1 of the Online Resource 1). One tissue block (one slide per staining) was evaluated from 47 patients. An additional block was used in six cases, resulting in a total number of 59 evaluated paraffin blocks. An overview of the evaluated tissue area is provided in Table 2.

Tissue samples were collected during the surgery and processed immediately after, fixed in $4 \%$ phosphatebuffered formaldehyde for 24 hours, embedded in paraffin, and cut into $3 \mu \mathrm{m}$ thick sections. The histopathological work-up included Haematoxylin-eosin (H\&E), estrogen and progesterone receptors (ER/PR), Cytokeratin 5/14, and Ki-67 immunohistochemical stainings according to automated standard protocols (Ventana Benchmark Ultra, Tucson, AZ). Immunohistochemistry for CD8 (Dako M7103), CD4 (Zytomed Systems 5033354), CD163 (medac diagnostika 163M-16), and duplex staining for CD3/CD20 (CD3: abcam ab52959, CD20: DAKO M0755) was performed using red and brown chromogenic labeling provided by Ventana.

A single representative block of the series was used for the 3D-reconstruction and robustness testing that addressed the variability of lobular structures and the concordance of immune cell evaluation across multiple sectioning levels (see Section 3.1). For this purpose, the entire block was sectioned into $3 \mu \mathrm{m}$ thick serial sections. The first 270 levels were stained for $\mathrm{H} \& \mathrm{E}$ and used for 3D histology reconstruction, and subsequent 100 sections were processed in 10 sets (of 10 sections each) of which the initial 6 consecutive slides were stained for CD8/p63 (CD8: Dako M7103, p63: medac diagnostica Z2003L).

Negative controls were treated identically, but omitting the primary antibody or replacing it by nonimmune sera of the same species. WSIs were acquired by Aperio AT2 scanner (Leica Microsystems, Wetzlar, Germany) at 40x magnification (resolution $0.253 \mu \mathrm{m} /$ pixel).

\subsection{Image Analysis}

The image analysis concept was focused on two aspects of immune cell evaluation where computer-assisted approaches provide an added value over visual inspection: (1) concordance testing of multiple sectioning levels across a block, and (2) evaluation of automatically detected ROIs, complementing the established practice of manually selecting representative fields for evaluation. This ROI detection approach enables expansion of the evaluated area, standardization of scoring criteria, and streamlining of the analysis process. The first aspect was addressed by a three-dimensional (3D) histology reconstruction of serial H\&E sections, performed using the Voloom software (microDimensions, Munich, 
Table 1 Composition of the reduction mammoplasty patient cohort and menstrual cycle phases. (*): for 5 patients in the luteal and 2 patients in the follicular phase of natural cycles (without oral contraceptives), the assignment to a cycle phase was a "best guess"-approximation due to reportedly irregular menses, $(* *)$ : parity unknown for 1 patient

\begin{tabular}{llllll}
\hline \multirow{2}{*}{ Cycle phase } & $\begin{array}{l}\text { Number of } \\
\text { patients }\end{array}$ & \multicolumn{2}{c}{$\begin{array}{l}\text { Age at surgery } \\
\text { Median }\end{array}$} & $\begin{array}{l}\text { Oral contra- } \\
\text { Range }\end{array}$ & $\begin{array}{l}\text { Percentage } \\
\text { nullipara }\end{array}$ \\
\hline \multirow{2}{*}{ luteal } & $20^{*}$ & 29 & $21-53$ & no & $35 \%$ \\
& 9 & 27 & $18-34$ & yes & $37.5 \%^{* *}$ \\
& & & & & \\
mid cycle & 4 & 28 & $21-45$ & no & $75 \%$ \\
& 4 & 27 & $22-32$ & yes & $100 \%$ \\
follicular & $9 *$ & 29 & $26-48$ & no & $55.6 \%$ \\
& 7 & 26 & $19-29$ & yes & $85.7 \%$ \\
\hline
\end{tabular}

Table 2 Total size of evaluated lobular area within the breast tissue (in $\mathbf{~ c m}^{2}$ ) per patient after automated detection [3] and quality assessment of ROIs. "StdDev" = standard deviation. The last column ("Multiple blocks") shows the range and the median (in brackets) for the six patients for which two blocks were considered (see Section 2.1).

\begin{tabular}{llllll} 
Staining & Range & Median & Mean & StdDev & Multiple blocks \\
\hline Ki-67 & $0.02-2.74$ & 0.72 & 0.88 & 0.70 & $0.36-2.74(1.18)$ \\
CD8 & $0.06-3.68$ & 0.78 & 0.92 & 0.72 & $0.36-1.48(1.10)$ \\
CD4 & $0.06-2.16$ & 0.74 & 0.86 & 0.56 & $0.38-1.60(1.08)$ \\
CD163 & $0.06-2.74$ & 0.74 & 0.86 & 0.62 & $0.38-1.72(0.92)$ \\
CD3/CD20 & $0.06-2.76$ & 0.78 & 0.92 & 0.70 & $0.32-2.76(0.86)$
\end{tabular}

Germany) in one out of the 53 clinically annotated cases (follicular cycle phase; on oral contraceptives). This was done in order to analyze how variable size, shape, and immune cell content of lobular areas considered as "representative lobules" can be across multiple consecutive sectioning levels.

The second aspect was addressed by an approach resembling and expanding the established practice of analyzing single sections: The analysis allowed including all evaluable lobular areas in a WSI, provided that they can be automatically detected in an individual stained section applying reproducible and adaptable criteria (e.g., minimal accepted size). A quality assurance step ensured exclusion of technically insufficient or tangentially sectioned small parts of lobules. In order to quantify immune cell numbers in lobular structures, we developed a modular workflow (see Fig. 1), combining automated regions of interest (ROIs) detection [3], high-resolution cell detection with a robust analysis module for nucleus detection (part of the Tissue Phenomics framework, Definiens AG, Munich, Germany) [5], and subsequent cell classification. For quality control, all automatically detected ROIs were verified by visual inspection of an expert. All correctly detected lobular areas (Table 2 of the Online Resource 1) were used for statistical analysis.
Detected cells were grouped into immune cells, positively stained with respective lineage markers, and negatively stained cells. The latter were further distinguished into epithelial cells and other (e.g., stromal) elements based on morphological features. The approach for Ki67 staining was adjusted considering that this marker is not cell lineage-specific. Based on published evidence of relevant distances for cytotoxic effector functions and chemokine mediated cell-cell communication [20], we classified each stained immune cell into one of three categories as "in contact with an epithelial cell" (no distance to the closest epithelial cell), "short distance to an epithelial cell" (distance to the closest epithelial cell less than two average cell diameters enabling communication via chemokines), and "in lobular stroma" (within lobular area but chemokine gradient sensing could not be possible $[27,28]$ ).

To investigate co-localization between different immunohistochemical markers, we applied existing co-registration methods $[43,4,37,36]$ to allow quantitative evaluation of corresponding regions. To enable full individual analysis of every separate slide, ROIs were individually identified [3] and corresponding areas for joint analysis were defined as overlapping regions (Fig. 1 of the Online Resource 1). This approach addressed a challenge frequently faced in object-based biomarker analyses with 


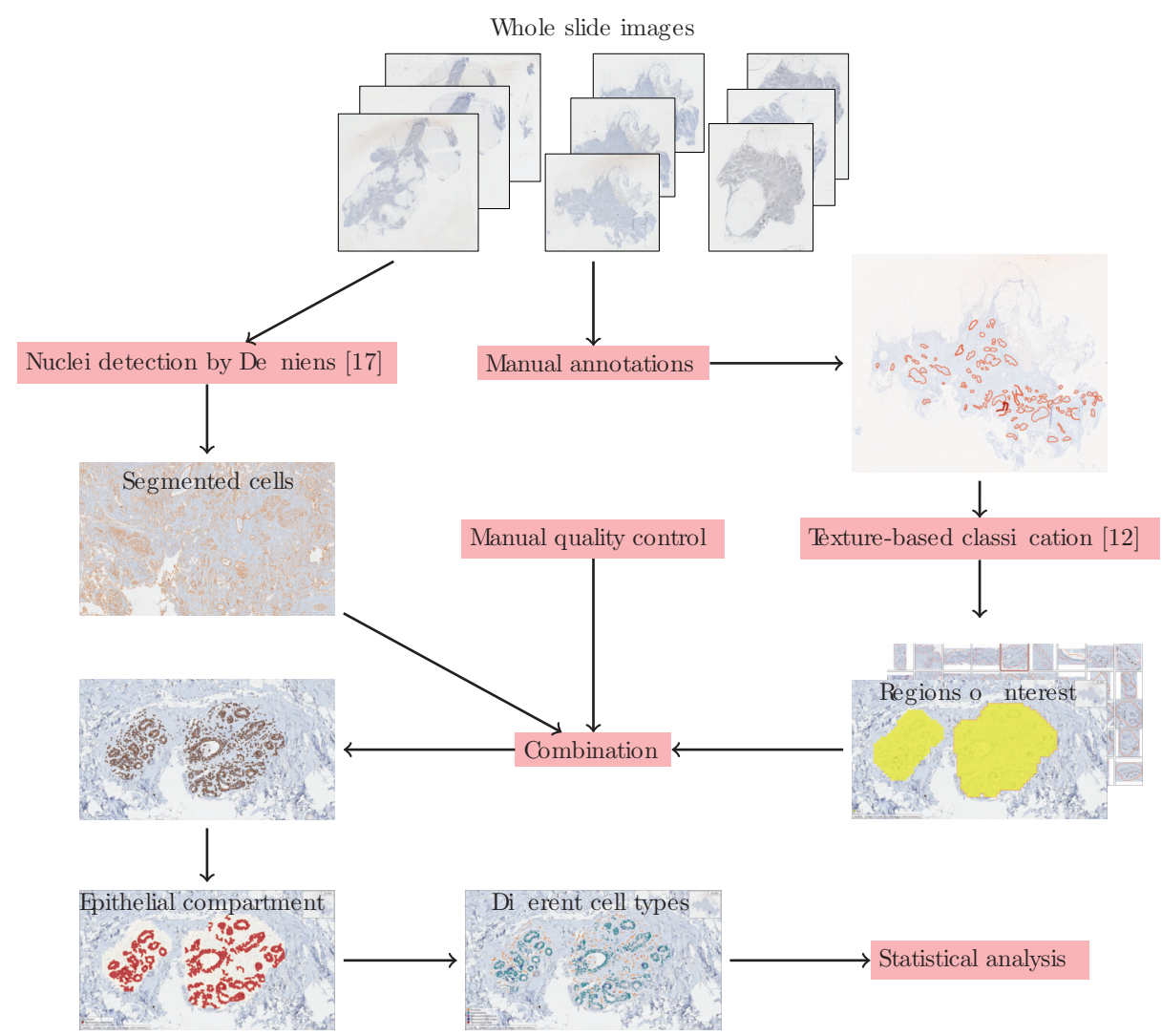

Fig. 1 Flow chart of image analysis process: A texture and machine learning based region classification detects the region of interests [3] and a Definiens software module was used to segment the nuclei [5]. Based on color information and spatial distances, the nuclei in regions of interest were classified into different cell types

multiple immunohistochemical staining methods, where the sectioning levels show corresponding tissue regions but may not exactly match in subsequent sections.

\subsection{Statistical considerations}

Due to the strongly varying size of automatically detected lobular areas, immune cell counts as well as the amount of $\mathrm{Ki}-67^{+}$cells were normalized by the number of epithelial cells. Comparisons between subgroups were performed using a nonparametric test (WilcoxonMann-Whitney) with accepted significance level $\alpha$ of 0.001. A detailed description of the statistical analysis and the definition of the menstrual cycle phases is provided in the Online Resource 1.

\section{Results}

3.1 Robustness of immune cell evaluation across multiple sectioning levels

The 3D histology reconstruction of breast glandular tissue (Fig. 2 a) confirmed that lobular structures can vary considerably across different sectioning levels. This supported the notion that a quantitatively defined reference unit complementing the descriptive term "lobule" is useful and that specifying objective criteria of epithelial areas for quantification increases robustness. Automatically detected lobular areas including about 200-300 epithelial cells were most consistent with the lower range of "lobule" cross-sections selected for analysis by pathologists (Fig. 2 b-e). Therefore, we set our threshold for minimal size of tangentially sectioned lobular structures to 250 epithelial cells, thereby defining ROIs considered for large-scale automated image analysis.

In addition, the immune-epithelial cell ratio (IC/EC) greatly improved robustness of the analysis compared to only immune cell counts per lobule. Serial sections of duplex staining quantifying the basal epithelial cells (p63) in combination with CD8 (Fig. 2 f) showed that corresponding ROIs in consecutive sections greatly vary in their epithelial cell content (Fig. 3, left y-axis, series of strongly dotted diamonds). In contrast, their normalized immune cell density (CD8/p63) remained relatively constant, independently of lobular size, shape, and epithelial cell content (Fig. 3, left y-axis, series 

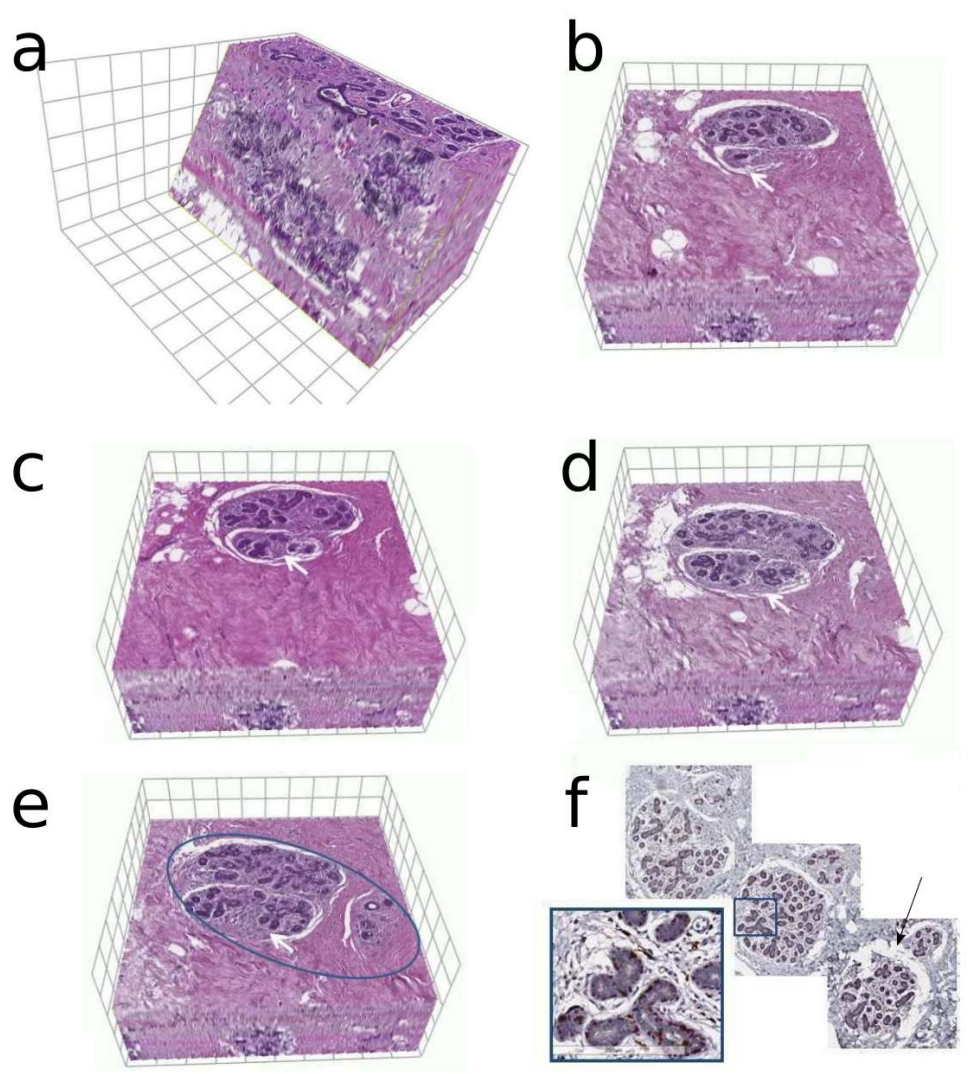

Fig. 2 Systematic evaluation of morphological variation across multiple sectioning levels. A 3D histology reconstruction of mammary gland tissue in multiple consecutive sections confirmed lobular areas strongly varying in shape and size across consecutive slides. a: 3D-view of the whole tissue block depicting the complexity of the glandular structure. b-e: Different levels showing how a "lobular area" develops from a single lobule (a) to an epithelial area composed of two lobules (b and c, white arrows indicate the second lobule), up to an area including a tangential section of a third lobule (asterisk), together composing a lobular ROI (oval blue outline). f: Consecutive $3 \mu \mathrm{m}$ thick immunohistochemistry slides, shown a CD8 (brown) and p63 (red) duplex stain with hematoxilin counterstain. Note the considerable variation in shape and size of the lobular components, including a shrinkage artifact in the third image (arrow)

of faintly dotted points). Taken together, these results showed that robustness of iTME evaluation can be improved by careful definition of evaluable ROIs and appropriate normalization of immune cell counts. Given that immune cell scoring requires consideration of variation between sectioning levels even in an anatomically well-defined healthy glandular structure, we anticipate that the iTME evaluation in much more heterogeneous and poorly differentiated tumor samples will hugely benefit from our image analysis workflow.

3.2 Variable lymphocyte patterns in different phases of the menstrual cycle

Immune cell infiltration in the normal breast tissue was variable and associated with the menstrual cycle. We observed a heterogeneous occurrence of immune cells within tissue samples of an individual and between pa- tients. This was consistent with our previous results in a subset of the present series, recently described in [1]. In general, there was a high number of $\mathrm{CD} 8^{+} \mathrm{T}-$ lymphocytes, about seven per 100 epithelial cells on average. The overall mean density of $\mathrm{CD} 8^{+} \mathrm{T}$-cells was significantly higher in the luteal than in the follicular phase of the menstrual cycle with 1.6 fold increase in patients not taking oral contraceptives $(p<0.001)$ and 1.4 fold increase $(p<0.001)$ in patients taking oral contraceptives (Fig. 4). This difference was predominantly driven by the $\mathrm{CD} 8^{+}$lymphocytes in close contact to the epithelial layer and less evident in the stromal infiltrates. The presence of potentially cytotoxic $\mathrm{CD} 8^{+}$ T-cells in direct contact with morphologically vital epithelial cells suggested an inactive or resting functional state, consistent with a presumable role in continuous immunosurveillance. Further, in patients using oral contraceptive, the $\mathrm{CD} 8^{+}$density was 1.1 fold higher re- 


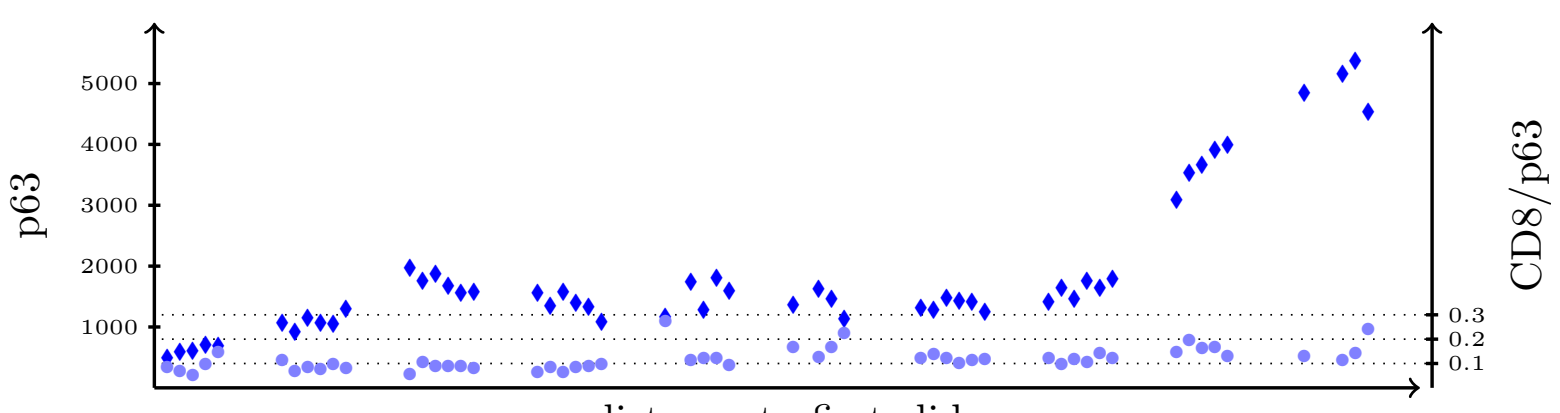

distance to first slide

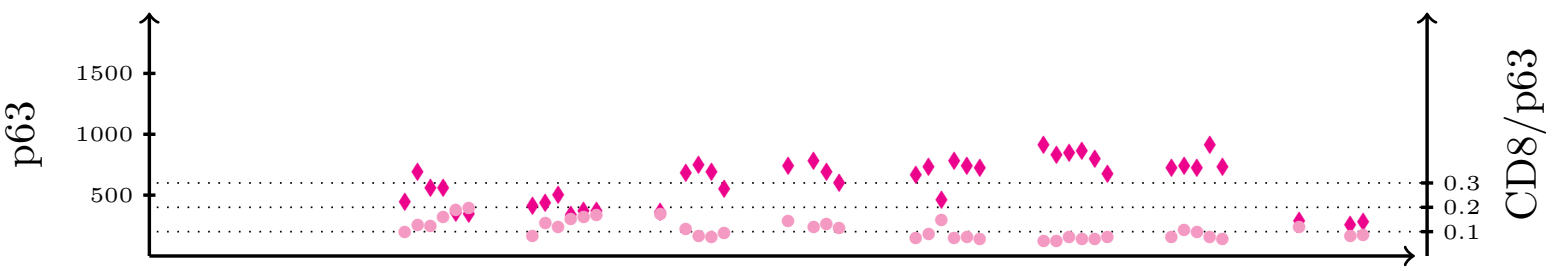

distance to first slide

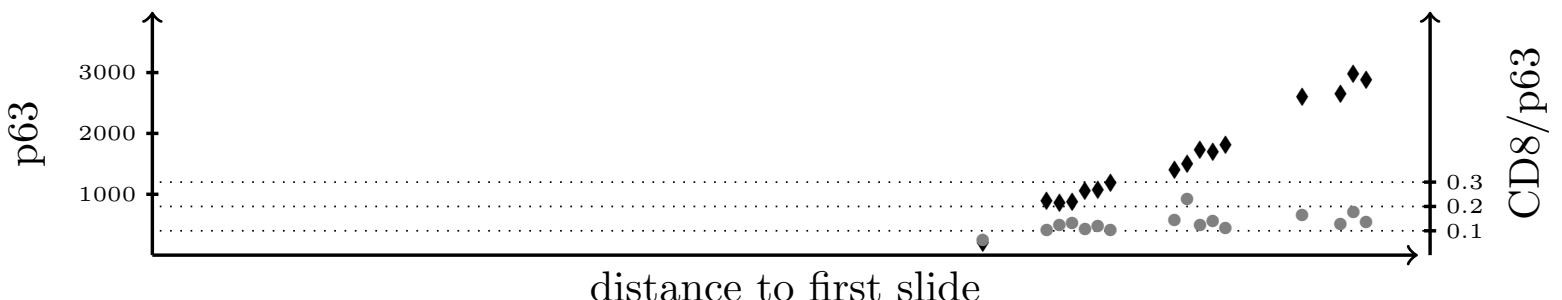

Fig. 3 Robustness of the ratio between $\mathrm{CD} 8^{+}$T-cells and $\mathrm{p} 63^{+}$basal epithelial cells in corresponding lobular areas of different size and shape in consecutive slides. Shown are three (more in Fig. 2 of the Online Resource 1) independent ROIs (different colors) in a single block of a patient who underwent reduction mammoplasty. Each dark diamond reflects an absolute p63+ basal epithelial cells count (left y-axis) and each light circle of the same color represents the CD8/p63 ratio (right y-axis) in the same ROI. Some lobular areas remained relatively constant across multiple sections (second row), whereas others changed in epithelial cell number (first and third row)

gardless of the cycle phase and 1.2 fold higher in the follicular phase than in patients not taking oral contraceptives. In contrast, the overall amount of $\mathrm{CD} 4^{+}$ T-helper cells was too small in the normal breast tissue (on average, about one CD4 ${ }^{+}$T-cells per 100 epithelial cells; see Fig. 3 of the Online Resource 1) to analyze their dependence on the menstrual cycle. CD20+ B-lymphocytes were also present, mostly at low numbers (on average, less than one B-cell per 100 epithelial cells), with the only exception of two cases where we observed focally higher densities of CD20 ${ }^{+}$cells in stromal localization (Fig. 4 of the Online Resource 1).

\subsection{Variation of $\mathrm{CD} 163^{+}$macrophages during the} menstrual cycle

$\mathrm{CD} 63^{+}$macrophages were present in high numbers, comparable with the amount of $\mathrm{CD}^{+}{ }^{+} \mathrm{T}$-lymphocytes (Fig. 5 of the Online Resource 1). The density of CD163 ${ }^{+}$ macrophages was significantly lower in the luteal than in the follicular phase (Table 1 of the Online Resource 1). In contrast to $\mathrm{CD}^{+}$lymphocytes, macrophages were not obviously co-localized with the epithelial cells. CD163 ${ }^{+}$ macrophage numbers were 1.1 fold increased in patients taking oral contraceptive compared to patients not taking oral contraceptive (significant). The spatial distribution of macrophages suggested less contact with individual epithelial cells than in the case of $\mathrm{CD}^{+} \mathrm{T}$ lymphocytes. This might indicate that $\mathrm{CD} 163^{+}$macrophages have a role in permanent maintenance of the tissue microenvironment including stromal areas.

$3.4 \mathrm{CD}^{+}$lymphocytes in context of epithelial proliferation

Given that $\mathrm{CD}^{+}$lymphocytes were more frequent in the menstrual cycle phase for which higher rates of proliferation had been previously described [13,41,34], we 

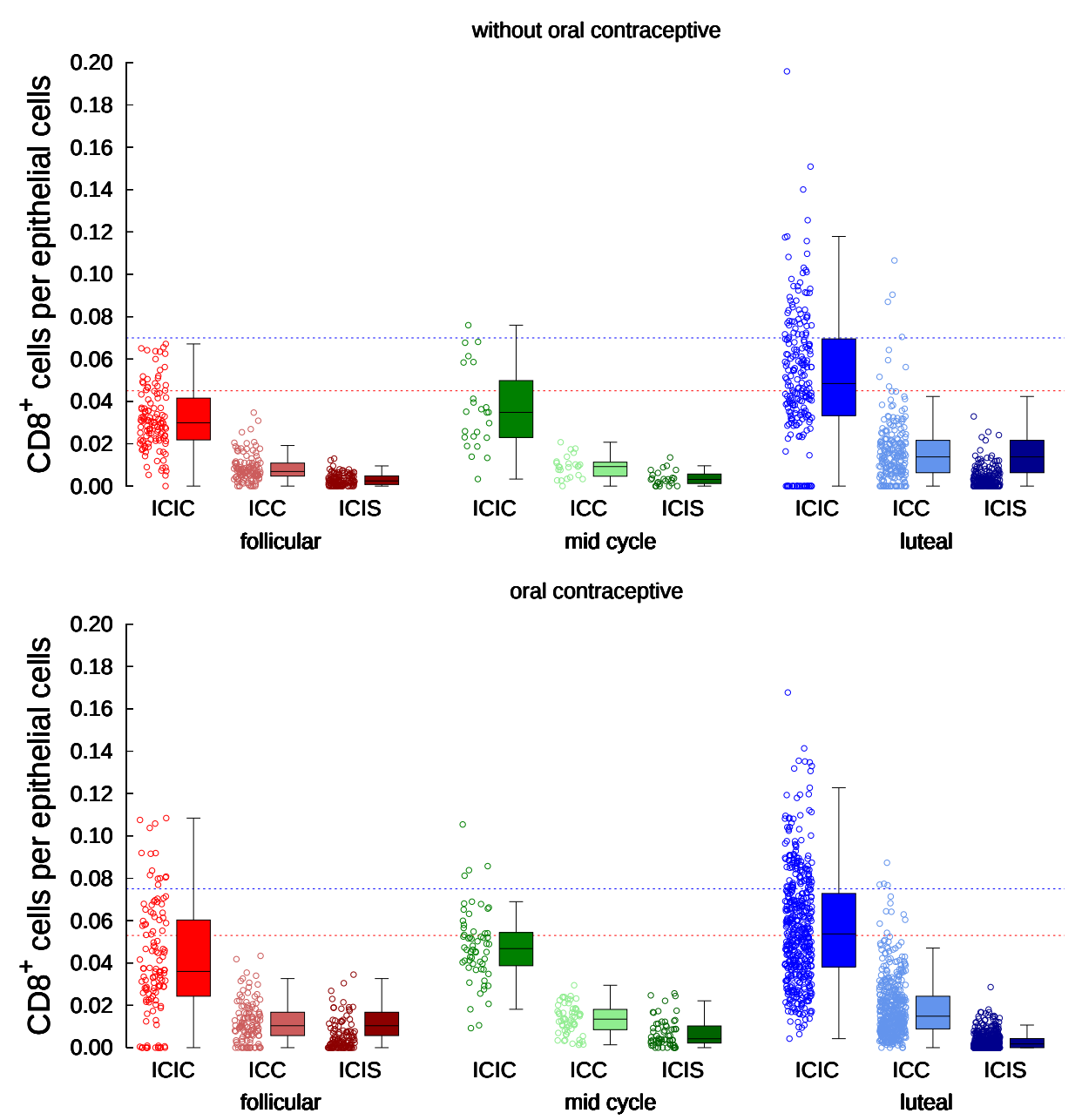

Fig. 4 Differences between follicular and luteal cycle phase in the number of CD8 + T-cells in contact with epithelial cells (ICIC), close to epithelial cells (ICC), and in lobular stroma (ICIS) displayed as ratio per epithelial cells (IC/EC) in the same lobule. Shown are the distribution, mean value, upper and lower quantile, as well as the standard deviation. The figure compares patients without taking oral contraceptives (top row) and patients taking oral contraceptive (bottom row). Dashed lines illustrate the average values of total immune cell count (i.e., ICIC + ICC + ICIS) over all ROIs (see Table 2 of the Online Resource 1) in the follicular (red) and luteal (blue) phases

analyzed whether focal peaks in epithelial cell turnover were co-localized with higher density of immune cells. Our results (Fig. 6 of the Online Resource 1) for nuclear Ki-67 staining were in agreement with published data, showing that proliferation is generally increased in the luteal phase [31]. Taking into account that this increase is especially strong in the second part of the luteal phase [2], we split this phase in two parts for more precise statistical analysis (see Online Resource 1). Coregistration results between $\mathrm{CD} 8$ and $\mathrm{Ki}-67$ stained sections showed that $\mathrm{CD}^{+}$lymphocytic infiltrates were not co-localized with peaks of epithelial proliferation (correlation coefficient: 0.030). A visual inspection by a pathologist of several images confirmed the accuracy of this automated analysis result, as shown in the representative examples of Fig. 5.
Assuming that increased cell turnover is associated with elevated risk for cell damage or aberrant cell divisions [29,23], it would be plausible that $\mathrm{CD} 8^{+}$cells could possibly be required in higher numbers close to areas of transient proliferative activity, such that a colocalization with areas of increased cell renewal in the luteal phase $[33,30]$ could be expected. However, our results do not support this expectation and may indicate that the majority of $\mathrm{CD}^{+}$cells are not actively involved in processes associated with local or temporal peaks of epithelial cell turnover, consistent with a resting functional state. 

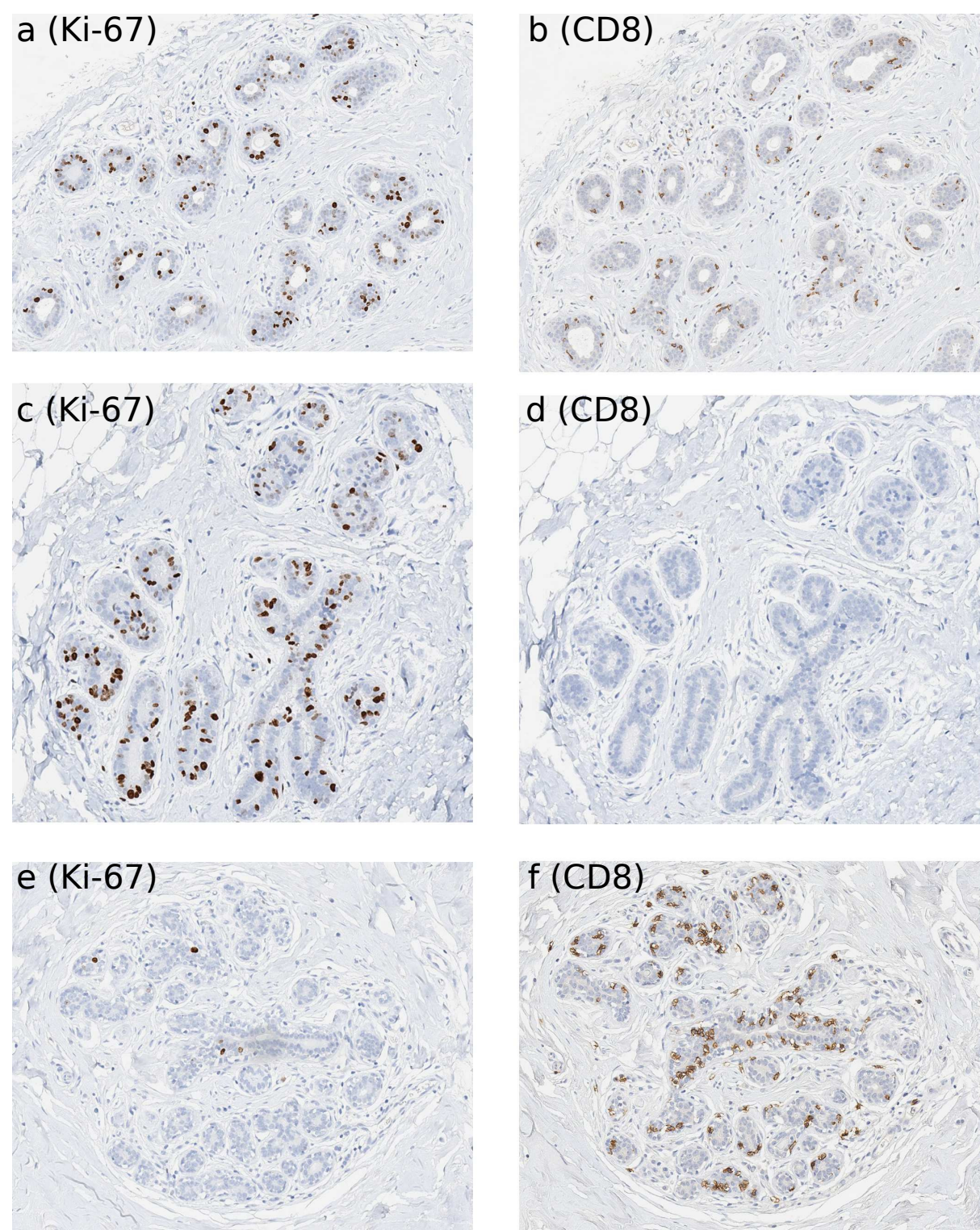

Fig. 5 a-b: ROI with high Ki-67 (left) and high CD8 (right) level. c-d: ROI with high Ki-67 (left) and low CD8 (right) level. e-f: ROI with low Ki-67 (left) and high CD8 (right) level

3.5 Spatial distribution of immune cells in normal breast

A comprehensive repository of the spatial distribution of immune cells in normal breast tissue, confirmed by image analysis, could serve as a reference to distinguish pathological conditions from normal immunosurveillance. As a major step towards such a reference data base, our workflow captured spatial aspects such as stromal localization of immune cells and provided the technological prerequisites to combine measures for lymphocyte subsets such as local CD4/CD8 evaluation in previously defined ROIs. CD $8^{+}$T-cells were surprisingly abundant in normal breast tissue, predominantly localized in direct contact to epithelial cells $(p<0.001)$, and appeared to vary under hormonal influence. Differently from this distribution pattern, $\mathrm{CD} 4^{+} \mathrm{T}$-cells were rare and in diffuse localization, and $\mathrm{CD}_{163^{+}}$macrophages occurred abundantly and widely spread. We propose integrating such quantitative and spatial aspects in future definitions of LLO. As one example for such combined spatial patterns, the two single lobules that were identified as "outliers" with high numbers of stromal B-cells were characterized by relatively low presence of intraepithelial CD3 ${ }^{+}$T-cells (Fig. 4 of the Online Resource 1). As another example, we envision that the combination of focal $\mathrm{CD}^{+}{ }^{+} \mathrm{T}$-cells in predominantly stromal localization, along with $\mathrm{CD}^{+} \mathrm{T}$-cell clusters in the neighborhood of destroyed or disintegrating lobular epithe- 
lium could be a distinguishing feature. This is based on the observation that this pattern was rarely present in the 53 normal breast samples of the current study, but repeatedly seen in an independent series of archival prophylactic mastectomy samples [1] in patients with $B R C A 1 / 2$ germline mutations (see two representative examples in Fig. 7 of the Online Resource 1). We propose such combined quantitative and spatial criteria to refine differences between normal and pathological conditions by large-scale image analysis.

\section{Discussion}

In this study, we described the distribution of immune cell subpopulations in normal breast tissue with focus on markers of growing relevance for oncoimmunology (CD4, CD8, CD163) and integrate their spatial patterns applying advanced image analysis. The high number of $\mathrm{CD}^{+}$T-lymphocytes and their dependence on the menstrual cycle and the use of oral contraceptives suggest the permanent presence of a T-cell population related to immunosurveillance under control of hormonal fluctuations. This can have implications for those diagnostic procedures where the nonmalignant components of the iTME are evaluated, for example in diabetic mastopathy [40], sclerosing lymphocytic lobulitis associated with autoimmune disease [17], and after prophylactic mastectomy [19].

Using the published quantitative definitions [16] accepting that one lobule is sufficient to diagnose LLO in an individual patient, more than $70 \%$ of patients in our data set would qualify for LLO. At the level of individual lobules, we estimated that a number of at least 100 $\mathrm{CD}^{+}$lymphocytes are contained in $17.3 \%$ of all ROIs that correspond to areas usually described as "representative lobules" with 250-2500 epithelial cells, 50-100 $\mathrm{CD}^{+}$lymphocytes are contained in further $27.6 \%$. Assuming that $\mathrm{CD}^{+}$lymphocytes are only a subset of all included lymphocytes, more than a quarter of normal lobules show LLO based on the definition "100 lymphocytes" [19]. Applying the definition of "more than 50 mononuclear cells per lobule" for moderate and 100 for severe LLO [16] to the CD8 and CD163 population about $81 \%$ of the normal lobules would show LLO. Since $\mathrm{CD}^{+}$and $\mathrm{CD}^{+} 63^{+}$cells are only a small subset of mononuclear cells, this is an underestimation. Based on the definition "at least four lymphocytes between the adjacent acini" [8], we estimated that about $20 \%$ of lobules in reduction mammoplasty samples would qualify for LLO. It should be questioned whether it is useful to define a potentially pathological condition like LLO in such a high percentage of asymptomatic women without clinical and histopathological abnormalities. Rather than claiming a generally applicable LLO definition, we propose to use conventional quantitative assessment to identify cases requiring further analysis, and to consider phenotypes, relative quantities, and localization of immune cells in order to contribute to a refinement of future LLO definitions. These might be different in various pathological conditions due to the individual underlying pathogenic mechanisms.

Reduction mammoplasty samples from patients considered healthy by all medical standards at the time of the surgery are strong evidence, but limitations of the approach should be mentioned. First, we cannot exclude that single patients may have been affected by breast cancer during their life after surgery. Second, it has been discussed that breast tissue from reduction mammoplasty may not be entirely representative for the "normal" female population with regard to slightly increased incidence of nonmalignant, non-proliferative lesions [9] and the occasional occurrence of premalignant lesions as described in a series from Brazil [32]. However, it can be considered the best type of tissue available for large-scale analysis, as opposed to needle biopsy specimens [9] that may miss some of the heterogeneity present in the iTME of breast glands (Fig. 2). We conclude that our study provides a solid approximation towards defining the range of normal immune cell presence. This is useful for future comparisons with different pathological conditions such as LLO in the context of genetic predisposition or manifest breast cancer.

In current practice, the evaluation of the inflammatory microenvironment in breast cancer $[35,10]$ is based on "Tumor infiltrating lymphocytes" (TILs) within the tumor mass and does neither consider the hormonal status of the patients (cycle phase, menopause, medication) nor the adjacent non-neoplastic tissue. Our results indicate that cycle phase and use of oral contraceptive therapy could potentially be relevant for evaluation, particularly in newly diagnosed patients without previous therapy-related effects. While changes up to 2-fold as observed in healthy patients may be a minor aspect for evaluation of solid tumor masses, where more than $60 \%$ of the stromal compartment can be TILs [35, 10], the patient history may be much more relevant for inflammatory changes in adjacent non-neoplastic tissue. For example, experience from colon cancer suggests that lymphocyte subsets at the invasive edge of tumors are more relevant for prognosis than the central tumor mass [14]. In this regard, our approach has the potential to support improvements of prognostic precision in the 
emerging era of oncoimmunology, for example, to evaluate inflammation close to benign precursor lesions [16, $18,21,6,26]$ or in preexisting glandular tissue adjacent to cancer areas of small early-stage tumors, where tumor is frequently closely related to non-neoplastic preexisting tissue.

In summary, this work provides an important proofof-concept that automated recognition of ROIs is possible in breast tissue and that large-scale image analysis of WSIs provides an added value by increasing reproducibility and observer independence. We anticipate a growing demand for immune cell evaluation beyond semi-quantitative scoring of TILs, such that technologies in immunoscoring for effector T-cells [10] and alternatively activated macrophages [39] will become increasingly important. As a long-term impact, further development of our approach will pave the way for broader applications of digital pathology in breast cancer biomarker evaluation, including automated detection of tumor, stroma, invasive edge, and adjacent normal tissues as relevant ROIs.

\section{Online Resource 1}

OnlineResource1.pdf contains additional information on methods as well as a collection of additional figures.

\section{Author's contributions}

NSS and FF designed the study, analyzed the results and prepared the manuscript. NSS, RS, AG, GF, and CW contributed to the concept and implementation of the image analysis workflow. NSS performed the statistical analysis. JCLA, HHK, and $\mathrm{HH}$ contributed to study design and edited the manuscript. NK established the staining and image acquisition workflow. MS and FF designed the collection protocol for the reduction mammoplasty material and obtained patient histories and informed patient consent. All authors approved the final manuscript.

Acknowledgements The authors thank Prof. Dr. Dr. U. Welsch, Department for Cell Biology, Biomedical Center $\mathrm{Mu}-$ nich, for his kind permission to use materials from previous studies that were collected during his term as Head of the Department for Microscopic Anatomy and Cytology (Chair II), Institute for Anatomy, Ludwig Maximilians University (LMU) Munich, Germany. The authors thank Pia Unterberger for organizing and storing archival material of the reduction mammoplasty series. The authors thank Gregory Apou for collaboration and scientific discussions on image analysis. The authors thank Priv.-Doz. Dr. M. Christgen, Institute of Pathology, Hannover Medical School, for breast pathology expertise. The authors thank the team of the Immunohistochemistry Laboratory, Institute for Pathology, Hannover Medical School for technical assistance, and the team of microDimensions, Munich, for help with 3D histology reconstruction.

\section{Compliance with Ethical Standards}

\section{Funding}

This study was funded by the German Federal Ministry of Education and Research (BMBF) for the collaborative SYSIMIT project, grant number

01ZX1308A-D.

\section{Conflict of interests}

Dr. Ralf Schönmeyer is a full-time employee of Definiens AG, Munich. All other authors declare that they have no conflict of interest.

\section{Ethical approval}

All procedures performed in studies involving use of surplus tissue samples and clinical information on human participants were in accordance with the ethical standards of the institutional research committee (Reference number of the Ethical Committee/institutional review board \#2063-2013) and with the 1964 Helsinki declaration and its later amendments or comparable ethical standards. Informed consent was obtained from all individual participants included in the study. This article does not contain any studies with animals performed by any of the authors.

\section{References}

1. Alfonso, J., Schaadt, N., Schönmeyer, R., Brieu, N., Forestier, G., Wemmert, C., Feuerhake, F., Hatzikirou, H.: In-silico insights on the prognostic potential of immune cell infiltration patterns in the breast lobular epithelium. Scientific reports 6 (2016)

2. Anderson, T., Battersby, S., King, R., McPherson, K., Going, J.: Oral contraceptive use influences resting breast proliferation. Hum Pathol 20, 1139-1144 (1989)

3. Apou, G., Schaadt, N.S., Naegel, B., Forestier, G., Schönmeyer, R., Feuerhake, F., Wemmert, C., Grote, A.: Detection of lobular structures in normal breast tissue. Computers Biol. Med. 74, 91-102 (2016)

4. Brieu, N., Goerner, M., Schmidt, G., Binnig, G.: Coregistering images of needle biopsies using multiple weighted landmarks (2014). URL https://www.google. ch/patents/US20140228707. US Patent App. 13/764,539 
5. Brieu, N., Pauly, O., Zimmermann, J., Schmidt, G.: Slide specific models for segmentation of differently stained digital histopathology whole slide images. SPIE Med Imaging (2016)

6. Chen, L., Tsang, J., Ni, Y., Chan, S., Chan, K., Zhang, S., Tse, G.: Lymphocyte subsets contribute to the degree of lobulitis and ductitis in sclerosing lymphocytic lobulitis of the breast. J Clin Pathol published online first November 18, 2015 (2015)

7. Chetty, R., Butler, A.: Lymphocytic mastopathy associated with lobular breast carcinoma. J Clin Pathol 46, 376-377 (1993)

8. Degnim, A., Brahmbhatt, R., Radisky, D., Hoskin, T., Stallings-Mann, M., Laudenschlager, M., Mansfield, A., Frost, M., Murphy, L., Knutson, K., et al.: Immune cell quantitation in normal breast tissue lobules with and without lobulitis. Breast Cancer Res Treat 144, 539-549 (2014)

9. Degnim, A., Visscher, D., Hoskin, T., Frost, M., Vierkant, R., Vachon, C., Pankratz, V., Radisky, D., Hartmann, L.: Histologic findings in normal breast tissues: comparison to reduction mammaplasty and benign breast disease tissues. Breast Cancer Res Treat 133, 169-177 (2012)

10. Denkert, C., Von Minckwitz, G., Brase, J., Sinn, B., Gade, S., Kronenwett, R., Pfitzner, B., Salat, C., Loi, S., Schmitt, W., et al.: Tumor-infiltrating lymphocytes and response to neoadjuvant chemotherapy with or without carboplatin in human epidermal growth factor receptor 2-positive and triple-negative primary breast cancers. J Clin Oncol 33, 983-991 (2015)

11. Douglas-Jones, A.: Lymphocytic lobulitis in breast core biopsy: a peritumoral phenomenon. Histopathol 48, 209$212(2006)$

12. Feuerhake, F., Sigg, W., Höfter, E., Dimpfl, T., Welsch, U.: Immunohistochemical analysis of bcl-2 and bax expression in relation to cell turnover and epithelial differentiation markers in the non-lactating human mammary gland epithelium. Cell Tissue Res 299, 47-58 (2000)

13. Feuerhake, F., Sigg, W., Höfter, E., Unterberger, P., Welsch, U.: Cell proliferation, apoptosis, and expression of bcl-2 and bax in non-lactating human breast epithelium in relation to the menstrual cycle and reproductive history. Breast Cancer Res Treat 77, 37-48 (2003)

14. Galon, J., Mlecnik, B., Bindea, G., Angell, H., Berger, A., Lagorce, C., Lugli Aand Zlobec, I., Hartmann, A., Bifulco, C., et al.: Towards the introduction of the immunoscore in the classification of malignant tumours. J Pathol 232, 199-209 (2014)

15. Grote, A., Abbas, M., Linder, N., Kreipe, H., Lundin, J., Feuerhake, F.: Exploring the spatial dimension of estrogen and progesterone signaling: detection of nuclear labeling in lobular epithelial cells in normal mammary glands adjacent to breast cancer. Diagnostic Pathol 9, doi: 10.1186/1746-1596-9-S1-S11 (2014)

16. Gulbahce, H., Vanderwerf, S., Blair, C., Sweeney, C.: Lobulitis in nonneoplastic breast tissue from breast cancer patients: association with phenotypes that are common in hereditary breast cancer. Hum Pathol 45, 78-84 (2014)

17. Haj, M., Weiss, M., Herskovits, T.: Diabetic sclerosing lymphocytic lobulitis of the breast. J Diabetes and its complications 18, 187-191 (2004)

18. Hartmann, L., Sellers, T., Frost, M., Lingle, W., Degnim, A., Ghosh, K., Vierkant, R., Maloney, S., Pankratz, V., Hillman, D., et al.: Benign breast disease and the risk of breast cancer. N Engl J Med 353, 229-237 (2005)
19. Hermsen, B., von Mensdorff-Pouilly, S., Fabry, H., Winters, H., Kenemans, P., Verheijen, R., van Diest, P.: Lobulitis is a frequent finding in prophylactically removed breast tissue from women at hereditary high risk of breast cancer. J Pathol 206, 220-223 (2005)

20. Huse, M., Quann, E., Davis, M.: Shouts, whispers and the kiss of death: directional secretion in t cells. Nature Immunol 9, 1105-1111 (2008)

21. Hussein, M., Hassan, H.: Analysis of the mononuclear inflammatory cell infiltrate in the normal breast, benign proliferative breast disease, in situ and infiltrating ductal breast carcinomas: preliminary observations. J Clin Pathol 59, 972-977 (2006)

22. Krueger, J., Wemmert, C., Sternberger, L., Bonnas, C., Dietmann, G., Gançarski, P., Feuerhake, F.: Combat or surveillance? evaluation of the heterogeneous inflammatory breast cancer microenvironment. J Pathol 229, 569578 (2013)

23. Labi, V., Erlacher, M.: How cell death shapes cancer. Cell death \& disease 6, e1675 (2015)

24. Lammie, G., Borow, L., Staunton, M., DA, L., Pages, G., Millis, R.: Sclerosing lymphocytic lobulitis of the breastevidence for an autoimmune pathogenesis. Histopathol 19, 13-20 (1991)

25. Lee, A., Happerfield, L., Millis, R., Borow, L.: Inflammatory infiltrate in invasive lobular and ductal carcinoma of the breast. Brit J Cancer 74, 796-801 (1996)

26. Lee, H., Park, I., Song, I., Shin, S., Kim, J., Yu, J., Gong, G.: Tertiary lymphoid structures: prognostic significance and relationship with tumour-infiltrating lymphocytes in triple-negative breast cancer. J Clin Pathol published online first October 16, 2015 (2015)

27. Lin, F., Butcher, E.: T cell chemotaxis in a simple microfluidic device. Lab on a Chip 6, 1462-1469 (2006)

28. Lin, F., Butcher, E.: Modeling the role of homologous receptor desensitization in cell gradient sensing. J Immnol 181, 8335-8343 (2008)

29. Liu, S., Edgerton, S.M., Moore, D.H., Thor, A.D.: Measures of cell turnover (proliferation and apoptosis) and their association with survival in breast cancer. Clin Cancer Res 7, 1716-1723 (2001)

30. Navarrete, M., Maier, C., Falzoni, R., Quadros, L., Lima, G., Baracat, E., Nazario, A.: Assessment of the proliferative, apoptotic and cellular renovation indices of the human mammary epithelium during the follicular and luteal phases of the menstrual cycle. Breast Cancer Res 7, R306-13 (2005)

31. Olsson, H., Jernström, H., Alm, P., Kreipe, H., Ingvar, C., Jönsson, P.E., Ryden, S.: Proliferation of the breast epithelium in relation to menstrual cycle phase, hormonal use, and reproductive factors. Breast Cancer Res Treat 40(2), 187-196 (1996)

32. Pitanguy, I., Torres, E., Salgado, F., Viana, G.: Breast pathology and reduction mammaplasty. Plastic reconstructive surgery 115, 729-734 (2005)

33. Potten, C., Watson, R., Williams, G., Tickle, S., Roberts, S., Harris, M., Howell, A.: The effect of age and menstrual cycle upon proliferative activity of the normal human breast. Br J Cancer 58, 163 (1988)

34. Ramakrishnan, R., Khan, S., Badve, S.: Morphological changes in breast tissue with menstrual cycle. Modern Pathol 15, 1348-1356 (2002)

35. Salgado, R., Denkert, C., Demaria, S., Sirtaine, N., Klauschen, F., Pruneri, G., Wienert, S., Van den Eynden, G., Baehner, F., Penault-Llorca, F., et al.: The evaluation of tumor-infiltrating lymphocytes (TILs) in breast cancer: recommendations by an International TILs Working Group 2014. Annals Oncol 26, 259-271 (2015) 
36. Schönmeyer, R., Brieu, N., Schaadt, N., Feuerhake, F., Schmidt, G., Binnig, G.: Automated Whole Slide Analysis of Differently Stained and Co-Registered Tissue Sections, pp. 407-412. Springer Berlin Heidelberg, Berlin, Heidelberg (2015)

37. Schönmeyer, R., Yigitsoy, M., Brieu, N.: Updating landmarks to improve coregistration as regions of interest are corrected (2015). URL http://www.google.ch/patents/ US9177378. US Patent 9,177,378

38. Schwartz, I., Strauchen, J.: Lymphocytic mastopathy. an autoimmune disease of the breast? Am J Clin Pathol 93, 725-730 (1990)

39. Sousa, S., Brion, R., Lintunen, M., Kronqvist, P., Sandholm, J., Mönkkönen, J., Kellokumpu-Lehtinen, P., Lauttia, S., Tynninen, O., Joensuu, H., et al.: Human breast cancer cells educate macrophages toward the $\mathrm{m} 2$ activation status. Breast Cancer Res 17, 1-14 (2015)
40. Thorncroft, K., Forsyth, L., Desmond, S., Audisio, R.A.: The diagnosis and management of diabetic mastopathy. The Breast Journal 13, 607-613 (2007)

41. Vogel, P., Georgiade, N., Fetter, B., Vogel, F., McCarty Jr, K.: The correlation of histologic changes in the human breast with the menstrual cycle. Am J Pathol 104, 23 (1981)

42. Wemmert, C., Krüger, J.M., Forestier, G., Sternberger, L., Feuerhake, F., Gançarski, P.: Stain unmixing in brightfield multiplexed immunohistochemistry. In: 2013 IEEE International Conference on Image Processing, pp. 1125-1129. IEEE (2013)

43. Yigitsoy, M., Schmidt, G., Binnig, G.: Hierarchical patchbased co-registration of differently stain histopathology slides. In: SPIE Medical Imaging. International Society for Optics and Photonics (2017) 